\title{
The Role of Noninvasive Endpoints in Predicting Long-Term Outcomes in Pulmonary Arterial Hypertension
}

\author{
Samantha L. Wronski ${ }^{1} \cdot$ Margaret Mordin $^{2}\left[\right.$ D Kim Kelley ${ }^{3} \cdot$ Rebekah H. Anguiano $^{4} \cdot$ Peter Classi $^{5} \cdot$ Eric Shen $^{5}$. \\ Scott Manaker ${ }^{6}$
}

Received: 25 July 2019 / Accepted: 29 October 2019 / Published online: 13 November 2019

(c) The Author(s) 2019

\begin{abstract}
Background Until recently, many clinical trials in patients with pulmonary arterial hypertension (PAH) evaluated exercise capacity with 6-minute walk distance (6MWD) as the primary endpoint. Common secondary endpoints include PAH functional class (FC), which assesses symptoms, and either brain natriuretic peptide (BNP) or the inactive N-terminal cleavage product of its prohormone (NT-proBNP), which assesses cardiac function.

Objective Examine the relationships among 6MWD, FC, and BNP/NT-proBNP measured at baseline or follow-up with long-term outcomes in PAH studies.

Methods Relevant literature from January 1990 to April 2018 were obtained by searching PubMed, Embase, and Cochrane. Articles in English reporting on associations between 6MWD, FC, or BNP/NT-proBNP and outcomes in PAH were identified. Each endpoint was evaluated individually. Prespecified inclusion and exclusion criteria were applied at level 1 (titles/ abstracts) and level 2 (full-text review).

Results The database search yielded 836 unique records; 65 full-text articles were reviewed. Twenty-five studies were eligible for inclusion. Findings supported the importance of measuring PAH noninvasive endpoints in predicting longterm outcomes. Patients with shorter or decreased 6MWD, poor (III/IV) or declining FC (e.g., from II to III), or elevated or increasing BNP/NT-proBNP had a higher risk of death and costly events (e.g., hospitalization, lung transplant). FC also predicted health care resource utilization and costs. Collectively, these endpoints establish risk groups that predict likelihood of complications from $\mathrm{PAH}$ or death.

Conclusion Assessment of 6MWD, FC, and BNP/NT-proBNP provides low-cost, efficient, and noninvasive means of predicting long-term health and economic outcomes in patients with PAH.
\end{abstract}

Keywords PAH $\cdot$ Noninvasive endpoint $\cdot$ Risk assessment

\section{Introduction}

With an estimated prevalence of 10.6-12.4 cases per million [1], pulmonary arterial hypertension $(\mathrm{PAH})$ is a rare

Margaret Mordin

mmordin@rti.org

RTI Health Solutions, Research Triangle Park, NC, USA

2 RTI Health Solutions, Ann Arbor, MI, USA

3 Rx Trusted Advisors, Phoenix, AZ, USA

4 Department of Pharmacy Practice, University of Illinois at Chicago, Chicago, IL, USA

5 United Therapeutics, Research Triangle Park, NC, USA

6 Department of Medicine, Perelman School of Medicine at the University of Pennsylvania, Philadelphia, PA, USA chronic and progressive disease characterized by increased pulmonary vascular resistance that can result in death due to right heart failure [2]. Numerous available treatments for PAH [3] have been evaluated in clinical trials using a variety of endpoints [4-6]. In the past two decades, PAH study design and duration shifted from short-term trials assessing noninvasive endpoints to long-term event-driven trials [7, 8].

Six-minute walk distance (6MWD), functional class (FC), and indicators of right ventricular function (i.e., brain natriuretic peptide $[\mathrm{BNP}] /$ the active $\mathrm{N}$-terminal cleavage product of its prohormone [NT-proBNP], described in Table 1) are 
Table 1 Description of noninvasive endpoints

\begin{tabular}{ll}
\hline Noninvasive endpoint & Description \\
\hline 6MWD & 6MWD assesses disease severity by measuring the distance an individual is able to walk over 6 min on a hard, flat \\
Surface [16] & Level of FC, determined according to WHO FC or NYHA FC, ranges from I-IV and is physician assessed [16]. WHO \\
WHO FC & FC was adopted in 1998 as a modified version of NYHA FC, which was developed in 1928 [62]. WHO FC classes are \\
NYHA FC & defined as follows [62]: \\
& I: Patients with PH in whom there is no limitation of usual physical activity; ordinary physical activity does not cause \\
increased dyspnea, fatigue, chest pain, or presyncope & \\
& II: Patients with PH who have mild limitation of physical activity. There is no discomfort at rest, but normal physical \\
& activity causes increased dyspnea, fatigue, chest pain, or presyncope \\
& III: Patients with PH who have a marked limitation of physical activity. There is no discomfort at rest, but less than \\
ordinary activity causes increased dyspnea, fatigue, chest pain, or presyncope & IV: Patients with PH who are unable to perform any physical activity at rest and who may have signs of right ventricular \\
failure. Dyspnea and/or fatigue may be present at rest, and symptoms are increased by almost any physical activity & BNP is a neurohormone released by the myocardium, predominantly in the ventricles secreted in response to changes in \\
pressure inside the heart as measured through a blood test. Studies may measure BNP directly or NT-proBNP, which is \\
the nonactive prohormone released from the same molecule that produces BNP [63]
\end{tabular}

$6 M W D$ 6-minute walk distance, $B N P$ brain natriuretic peptide, $F C$ functional class, $N T$-proBNP N-terminal-prohormone BNP, NYHA $F C$ New York Heart Association Functional Class, $P H$ pulmonary hypertension, WHO FC World Health Organization Functional Class

among the commonly used short-term primary and secondary noninvasive endpoints in clinical PAH trials $[9,10]$. In a literature review examining 126 pulmonary hypertension (PH) clinical trials (78\% in PAH) from 1985 to 2013, surrogate measures were primary endpoints in $95 \%$ of trials and secondary endpoints in $33 \%$ of trials [9]. 6MWD and FC were among the noninvasive endpoints that were used significantly more frequently $(P<0.0001)[9]$. The latest 2015 European Society of Cardiology/European Respiratory Society treatment guidelines [11] and registry studies such as COMPERA [12] and REVEAL [13] also include 6MWD, $\mathrm{FC}$, and BNP/NT-proBNP as important components of risk assessment. Collectively, 6MWD, FC, and BNP/NT-proBNP serve as measurable prognostic indicators of the distal outcomes of morbidity and mortality that may be assessed early in order to determine treatment course and improve outcomes $[14,15]$. However, the clinical relevance and ability of these noninvasive endpoints to consistently correlate with key indicators of disease progression, such as hospitalization and death, has received mixed support [16-25]. This, coupled with improvements in survival and quality of life that have allowed recent clinical trials to follow patients with PAH for 4-6 years [7], has led to the prominence of mortality and morbidity as endpoints.

Morbidity and mortality, a term reflecting clinical worsening and disease progression [16, 23, 26], provide a robust demonstration of efficacy, safety, and long-term benefits of treatments for PAH [23]. The use of clinical worsening or disease progression as a primary endpoint in phase 3 trials was endorsed by the Task Force on End Points and Clinical Trial Design of both the Fourth and Fifth World Symposium on Pulmonary Hypertension and the 2008 Dana Point Task Force on End Points and Clinical Trial Design [16].
However, comparison of treatment efficacy across trials may be hindered by the varying definitions used for clinical worsening, as seen when comparing the definitions used in the AMBITION [27], GRIPHON [28], SERAPHIN [29], and FREEDOM EV [30-32] clinical trials. While it has been argued that the composite endpoint of clinical worsening is more clinically meaningful than noninvasive endpoints [19, 25], all four trials include 6MWD and FC in their definitions of clinical worsening, despite other differences. Additional components in the definition of clinical worsening, such as death, hospitalization, and lung transplant, require long-term follow-up to assess, and despite clearly indicating clear and undisputable indicators of ultimate treatment efficacy and safety, they cannot be used to assess clinical risk in the day-to-day care of patients with PAH that guide treatment decisions.

There is a need to revisit the optimal duration of future trials [7] and include clinically meaningful endpoints that reflect how patients feel and function [33]. In addition, the use of universal endpoints in PAH clinical trials and observational studies would better inform health care providers, decision makers, and payers on the value of targeted pharmacotherapies and combination therapies for patients with PAH [16]. 6MWD, FC, and BNP/NT-proBNP are universal endpoints, routinely used in clinical risk assessment, that can be assessed short-term (12-16 weeks [23]). The present review examines the value of 6MWD, FC, and BNP/ NT-proBNP by summarizing the literature supporting the relationship between these noninvasive endpoints and longterm clinical and economic outcomes. 


\section{Methods}

A literature review was conducted on April 13, 2018, in PubMed, Embase, and the Cochrane Database of Systematic Reviews using a search strategy (Table 2) that included Medical Subject Headings (MeSH) and key words for disease (e.g., pulmonary arterial hypertension), endpoints (e.g., 6MWD, FC, BNP), clinical importance (e.g., survival, mortality), and economic importance (e.g., costs, readmission, economics). Inclusion criteria incorporated studies published after January 1, 1997, in English and human subjects; comments, letters, or editorials were excluded. Bibliographies of relevant review articles were reviewed for any pertinent articles unidentified in the original search. To obtain information from relevant unpublished studies, a search of 2016-2017 conference abstracts via Embase was performed, including the American Thoracic Society International Conference, American College of Chest Physicians (CHEST) Annual Meeting, CHEST World Congress Annual Meeting, and the International Society for Pharmacoeconomics and Outcomes Research International Meeting.

Table 2 PubMed search strategy (search conducted April 13, 2018)

\begin{tabular}{|c|c|c|}
\hline Search number & Search terms & Number of results \\
\hline \multicolumn{3}{|l|}{ Disease } \\
\hline 1 & $\begin{array}{l}\text { "Familial Primary Pulmonary Hypertension”[Majr] OR "pulmonary arterial hypertension”[Title/ } \\
\text { Abstract] OR “primary pulmonary hypertension”[Title/Abstract] OR “idiopathic pulmonary } \\
\text { hypertension”[Title/Abstract] }\end{array}$ & 9301 \\
\hline \multicolumn{3}{|l|}{ Endpoints } \\
\hline 2 & 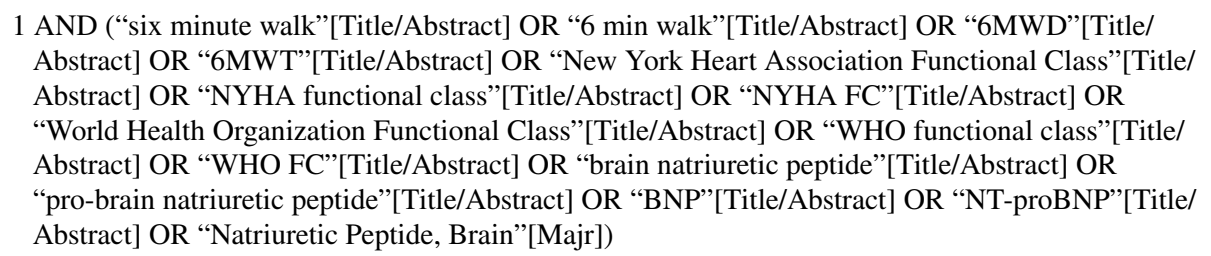 & 1208 \\
\hline \multicolumn{3}{|c|}{ Clinical importance } \\
\hline 3 & 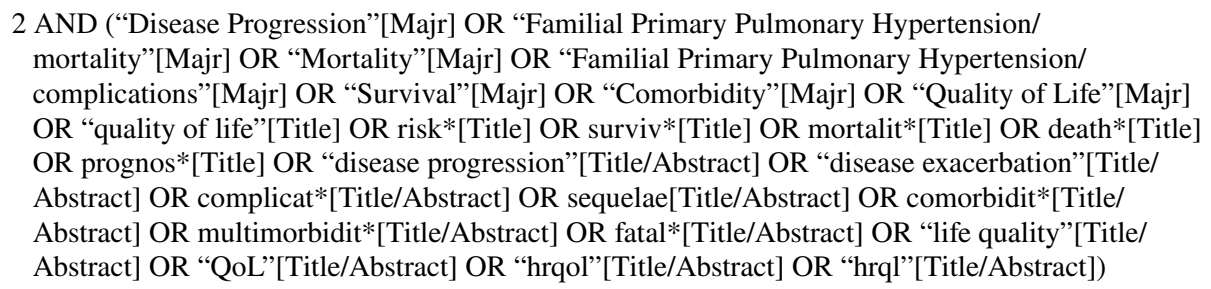 & 370 \\
\hline \multicolumn{3}{|c|}{ Economic importance } \\
\hline 4 & 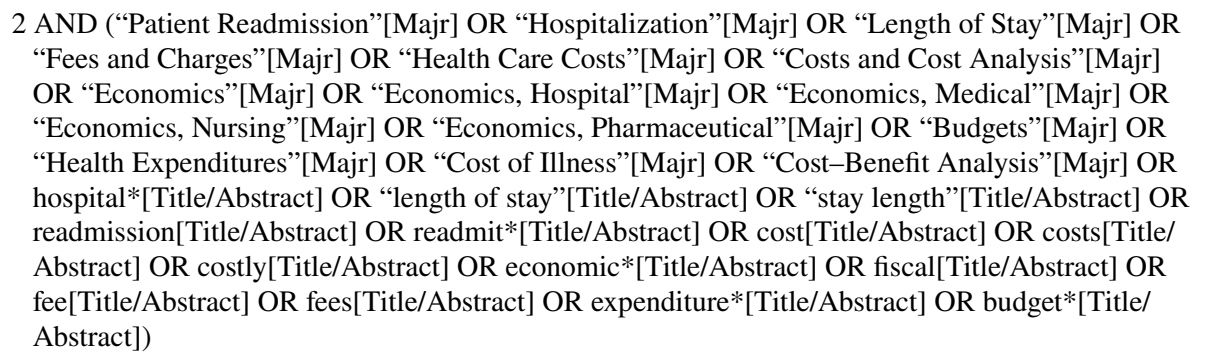 & 172 \\
\hline \multicolumn{3}{|l|}{ Exclusions } \\
\hline 5 & “Animals”[MeSH] NOT “Humans”[MeSH] & $2,060,466$ \\
\hline 6 & “Comment”[Publication Type] OR “Letter”[Publication Type] OR “Editorial”[Publication Type] & $1,104,425$ \\
\hline 7 & $\begin{array}{l}\text { (“Child”[MeSH] OR “Infant”[MeSH] OR “Adolescent”[MeSH] OR child*[Title/Abstract] OR } \\
\text { infant*[Title/Abstract] OR newborn*[Title/Abstract] OR adolescen*[Title/Abstract]) NOT } \\
\text { (“Adult”[MeSH] OR adult*[Title/Abstract] OR elder*[Title/Abstract] OR senior citizen*[Title/ } \\
\text { Abstract] OR middle age*[Title/Abstract]) }\end{array}$ & 937,574 \\
\hline \multicolumn{3}{|l|}{ Total } \\
\hline 8 & (\#3 OR \#4) NOT (\#5 OR \#6 OR \#7) & 460 \\
\hline
\end{tabular}

Search terms and limits were adapted for searching in Embase and the Cochrane Database of Systematic Reviews. Limits include 1997-present; English; humans; adults; no comments, letters, editorials 
Titles and abstracts of records were reviewed (level 1 screening) according to the objectives and inclusion and exclusion criteria. Included studies, defined using PICOS (population, intervention, comparison, outcome, study type), had the following:

- A primarily adult population ( $\geq 18$ years) with PAH from a WHO group 1 etiology

- Any intervention or comparator

- At least one of the noninvasive endpoints-6MWD, FC, BNP/NT-proBNP (Table 1) - and reported on the relationship between a noninvasive endpoint and a clinical or economic outcome of interest (note that the literature was searched for individual associations between each of the endpoints and PAH outcomes)

- An interventional (e.g., randomized controlled trials) or noninterventional (e.g., observational, prospective, retrospective, database, and/or registry studies) design, with $\geq 75$ patients, or a relevant literature review.

Full texts of included studies were reviewed (level 2 screening) using the same relevance criteria applied at level
1. That is, full-text articles were reviewed in detail, and the inclusion and exclusion criteria applied at level 1 (title/ abstract screening) were applied to evaluate the appropriateness for inclusion.

\section{Results}

\section{Literature Review}

Figure 1 summarizes the literature review, which identified 836 unique studies for level 1 screening, including 64 conference abstracts and 1 study identified through desktop research. Of these, 65 records were selected for level 2 screening; no conference abstracts were deemed eligible for inclusion. Twenty-five studies, summarized in Table 3, were selected for inclusion according to predefined inclusion/exclusion criteria. Although outcomes, such as risk of death or the combined endpoint of risk of death or lung transplant, were consistently defined across the literature, clinical worsening was defined differently in each of the three studies evaluating it as an outcome [2, 34, 35]; definitions used are noted in Table 3.
Fig. 1 Literature review flow diagram

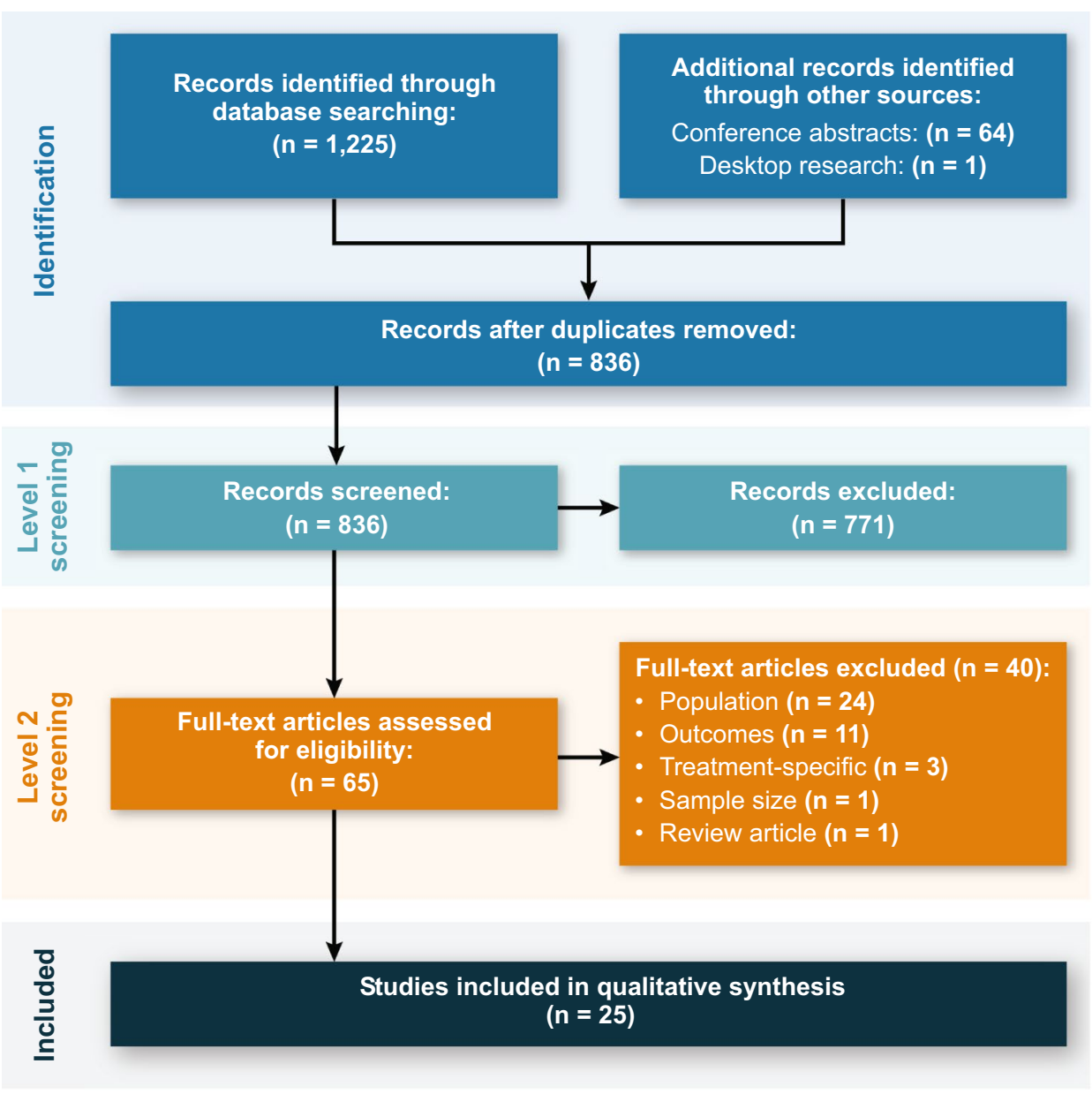




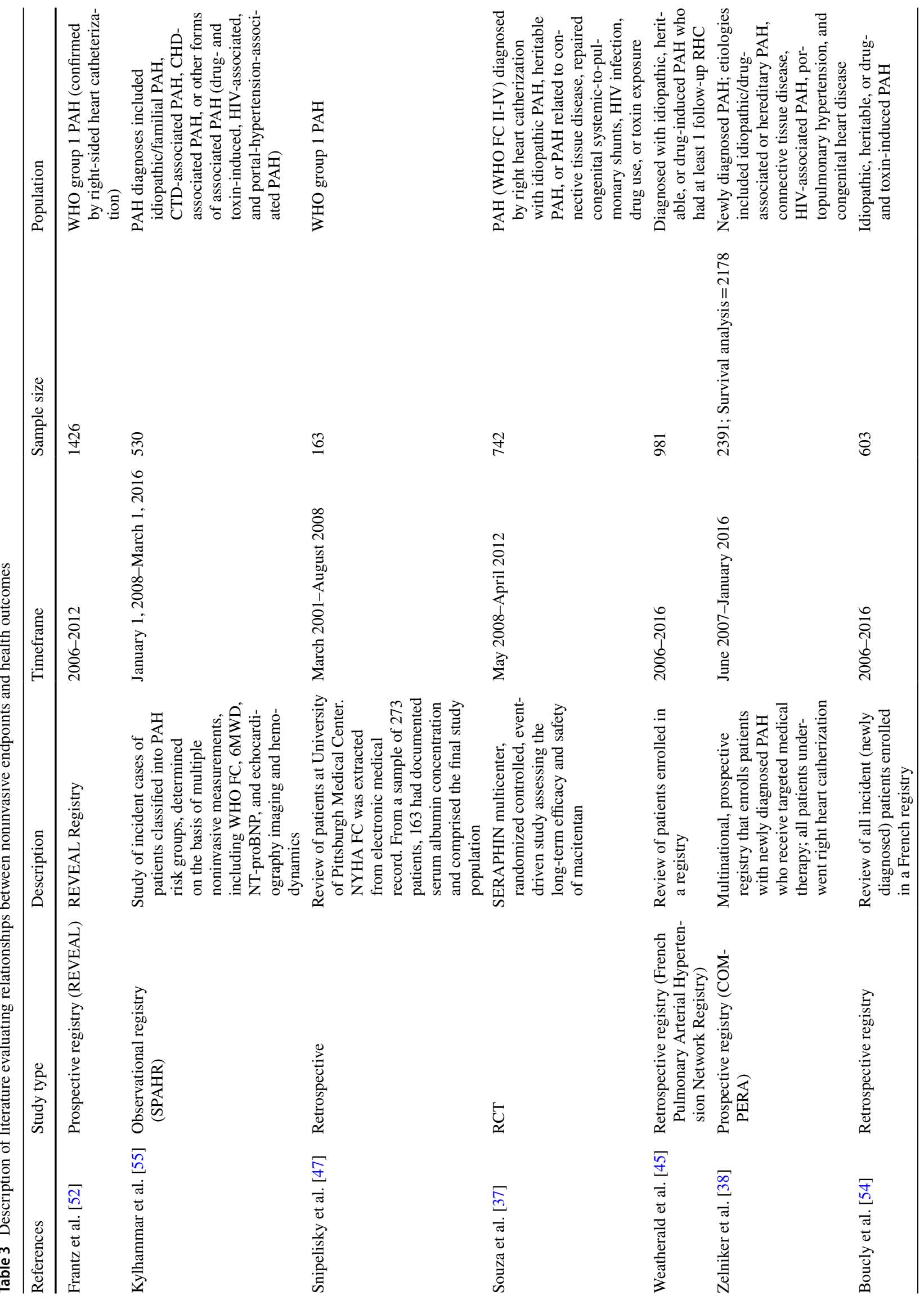



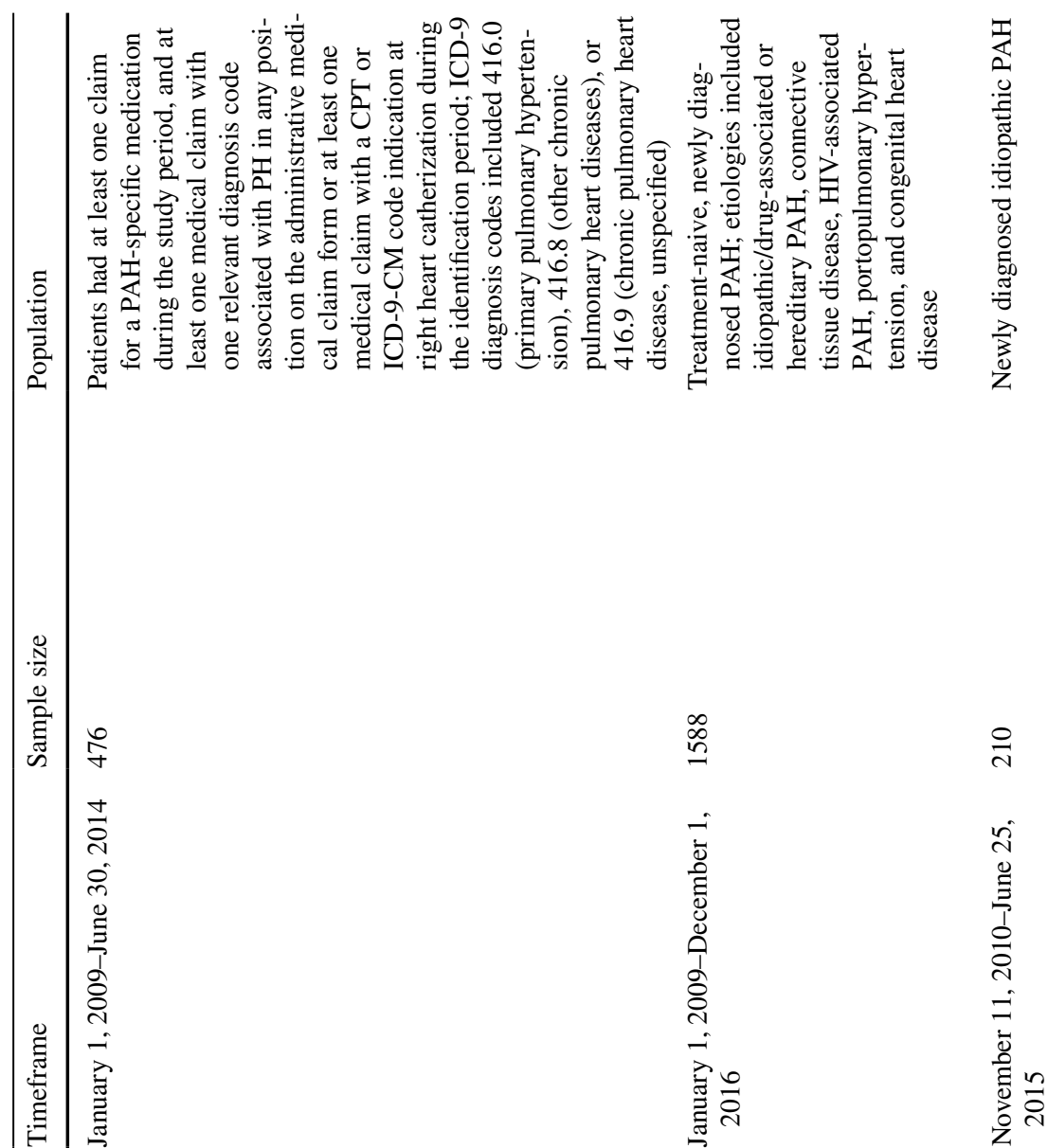

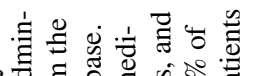

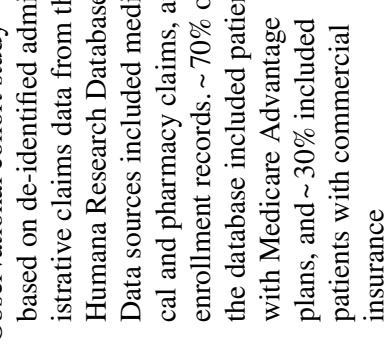

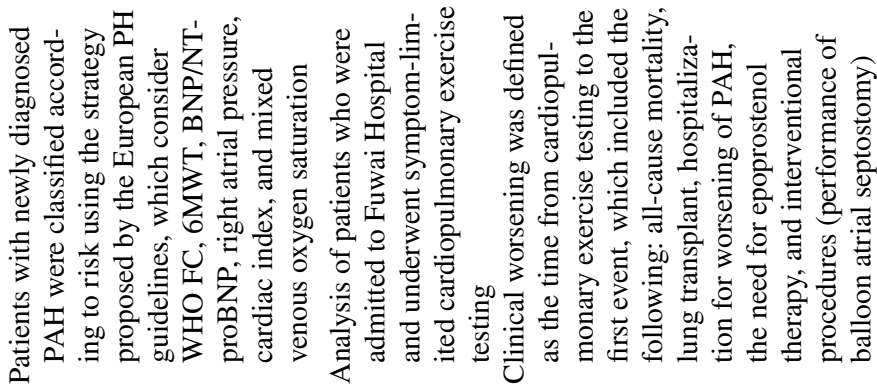

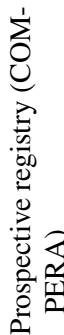

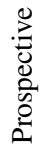

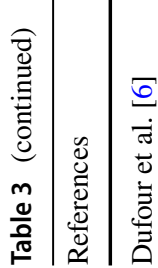

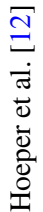

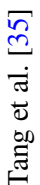



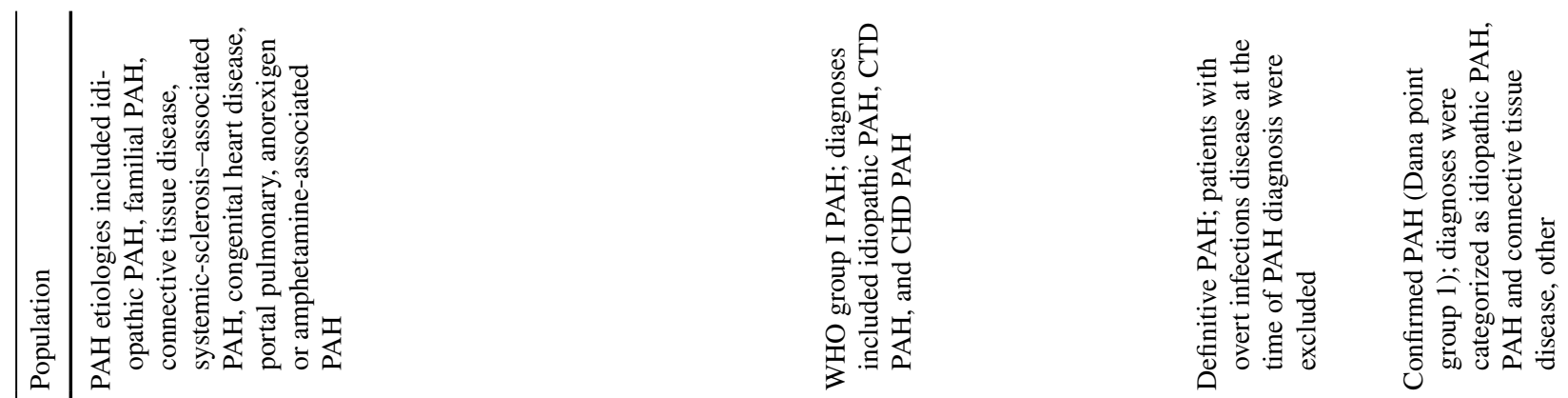

8

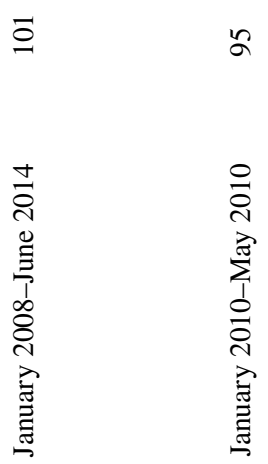

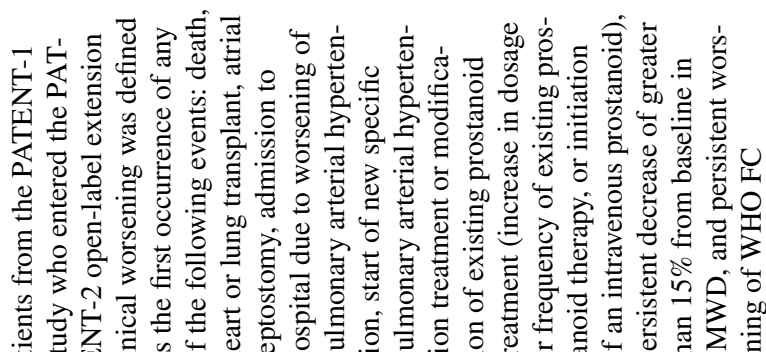

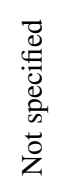

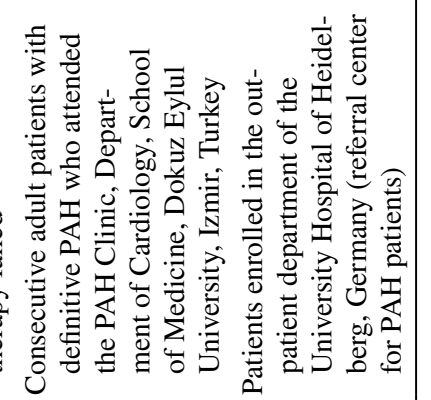

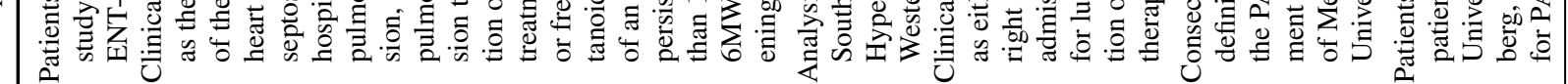

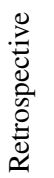

0
0
0
0
0
0

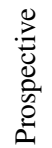

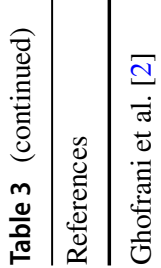

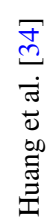

$\square$
0
0
$\overline{0}$
0
0
0
0
0
0

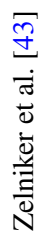




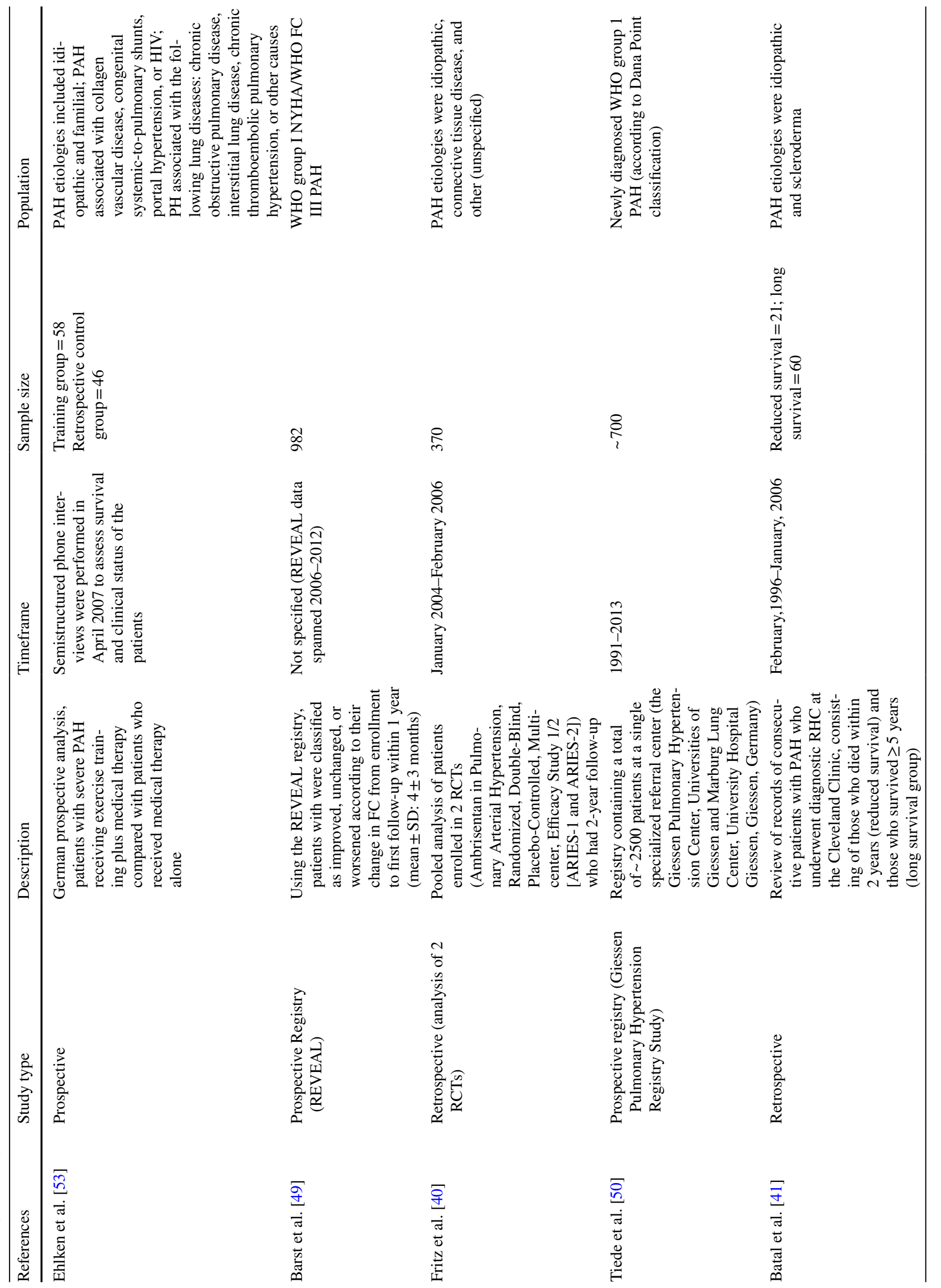




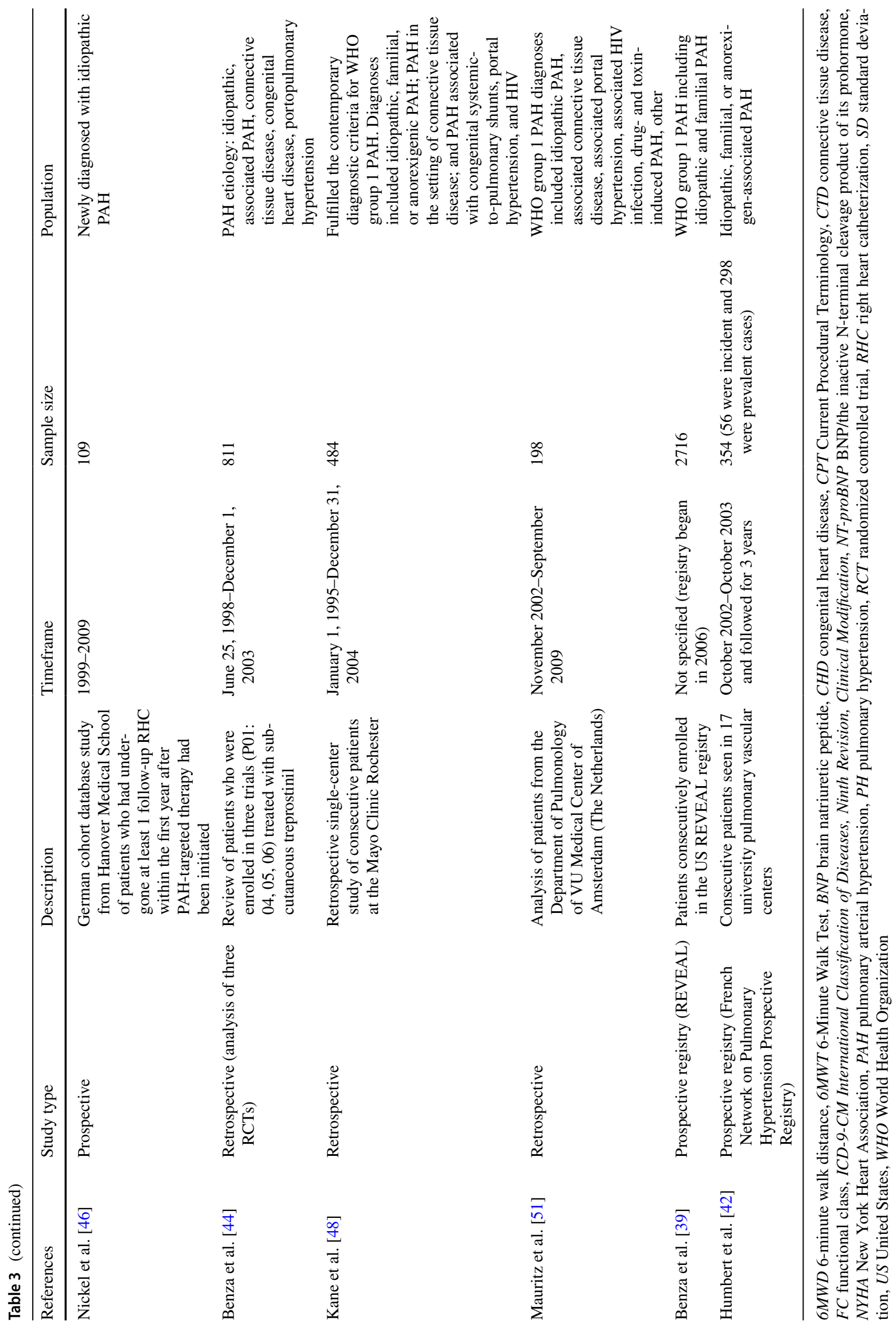




\section{MWD}

Thirteen studies evaluated the relationship between 6MWD and death $(n=10)$, death or lung transplant $(n=3)$, PAHrelated death or hospitalization $(n=1)$, and risk of experiencing a costly event indicative of clinical worsening $(n=2)$ (Table 4).

\section{MWD and Risk of Death}

Risk of death was increased among patients with 6MWD that was shorter [2,36], below the median $(<380 \mathrm{~m})$ [2], or in lower quartiles at baseline (reference: Q1 $\leq 300 \mathrm{~m}$ ) [37]. Specifically, risk of death at 1 year was increased among patients with shorter 6MWD [38] or 6MWD $<165 \mathrm{~m}$ at baseline [38, 39] and decreased among patients with $6 \mathrm{MWD} \geq 440 \mathrm{~m}$ at baseline [39]. Risk of death within 2 years was increased among patients with 6MWD that was shorter or in lower quartiles at baseline [40]. Further, $6 \mathrm{MWD} \leq 250 \mathrm{~m}$ at baseline was independently associated with an increased risk of patients dying within 2 years relative to patients surviving $\geq 5$ years [41]. Risk of death was also increased at 3 years [42] and 4 years [43] among patients with shorter 6MWD at baseline.

At follow-up, risk of death was increased among patients with 6MWD that was shorter [2], in lower quartiles (reference: Q1 $\leq 348 \mathrm{~m}$ ) [37], or below the median (defined

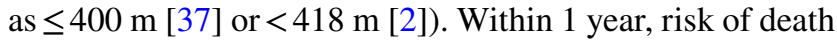
was increased among patients with $6 \mathrm{MWD}$ that was $<165 \mathrm{~m}$ [38]. Risk of death within 2 years was increased among patients with 6MWD that was shorter or in lower quartiles at 12-week assessment [40]. At 3 years, risk of death was increased among patients with smaller improvements in 6MWD between baseline and the 12-week follow-up compared with patients with $\geq 20 \mathrm{~m}$ increases in 6MWD [44].

\section{MWD and Risk of Death or Lung Transplant}

Risk of death or lung transplant was increased among patients with $6 \mathrm{MWD}$ that was shorter $[34,45]$ or below cutoff at baseline $(\leq 342 \mathrm{~m})$ [34]. Risk of death or lung transplant at 5 years was increased among patients with shorter baseline 6MWD [46].

At follow-up, risk of death or lung transplant was higher among patients with 6MWD that was shorter [45] or declined $\geq 35 \mathrm{~m}$ or $\geq 8 \%$ [34].

\section{MWD and Risk of PAH-Related Death or Hospitalization}

Risk of PAH-related death or hospitalization was increased among patients with 6MWD in lower quartiles at baseline (reference: Q1 $\leq 300 \mathrm{~m}$ ) [37]. At follow-up, risk was increased among patients with 6MWD in lower quartiles or below the median $(\leq 400 \mathrm{~m})$ [37].

\section{MWD and Risk of Clinical Worsening}

Risk of clinical worsening increased among patients with $6 \mathrm{MWD}$ that was shorter [2,34] or $\leq 342 \mathrm{~m}$ at baseline [34]. Risk was higher among patients with shorter [2] or decreasing 6MWD at follow-up [2, 34].

\section{FC}

Sixteen studies evaluated the relationship between FC and death $(n=9)$, death or lung transplant $(n=4)$, experiencing a costly event indicative of clinical worsening $(n=3)$, using health care resources $(n=2)$, and incurring health care costs $(n=1)$ (Table 4).

\section{FC and Risk of Death}

Patients with an increased risk of death at follow-up had more severe baseline FC (III/IV) [2, 36, 47], with highest risk of death within 1 year specifically among FC IV patients [39]. Further, FC IV symptomatology at baseline was independently associated with an increased likelihood of reduced survival (dying within 2 years) in univariate and multivariate analysis excluding initial PAH therapy [41]. Risk of death within 3 years was significantly higher for patients with more severe FC (III/IV) at baseline [42, 44]. Within 5 years, risk of death was higher for FC III or IV patients at baseline and increased $69 \%$ per class [48].

Risk of death was also predicted by more severe FC (III/ IV) at follow-up [2]. Patients who improved at least one FC from baseline to follow-up had a similar risk of death compared with patients whose FC did not improve, but patients who improved from FC III/IV to I/II at follow-up had a reduced risk of death compared with patients who remained in FC III/IV at both time points [2]. Risk of death at 3 years was higher for patients whose FC worsened or remained unchanged compared with those whose FC improved within 1 year of enrollment [49].

\section{FC and Risk of Death or Lung Transplant}

For the combined endpoint of risk of death or lung transplant, risk was higher among patients with more severe FC (III/IV) at baseline in studies examining FC [35, 45]. Risk of death or lung transplant within 5 years was higher for patients with more severe FC (III/IV) at baseline [46].

Risk of death or lung transplant was also predicted by more severe FC (III/IV) [45] at follow-up and changes in FC between baseline and follow-up. Risk of death or lung transplant within 5 years was increased for patients whose 


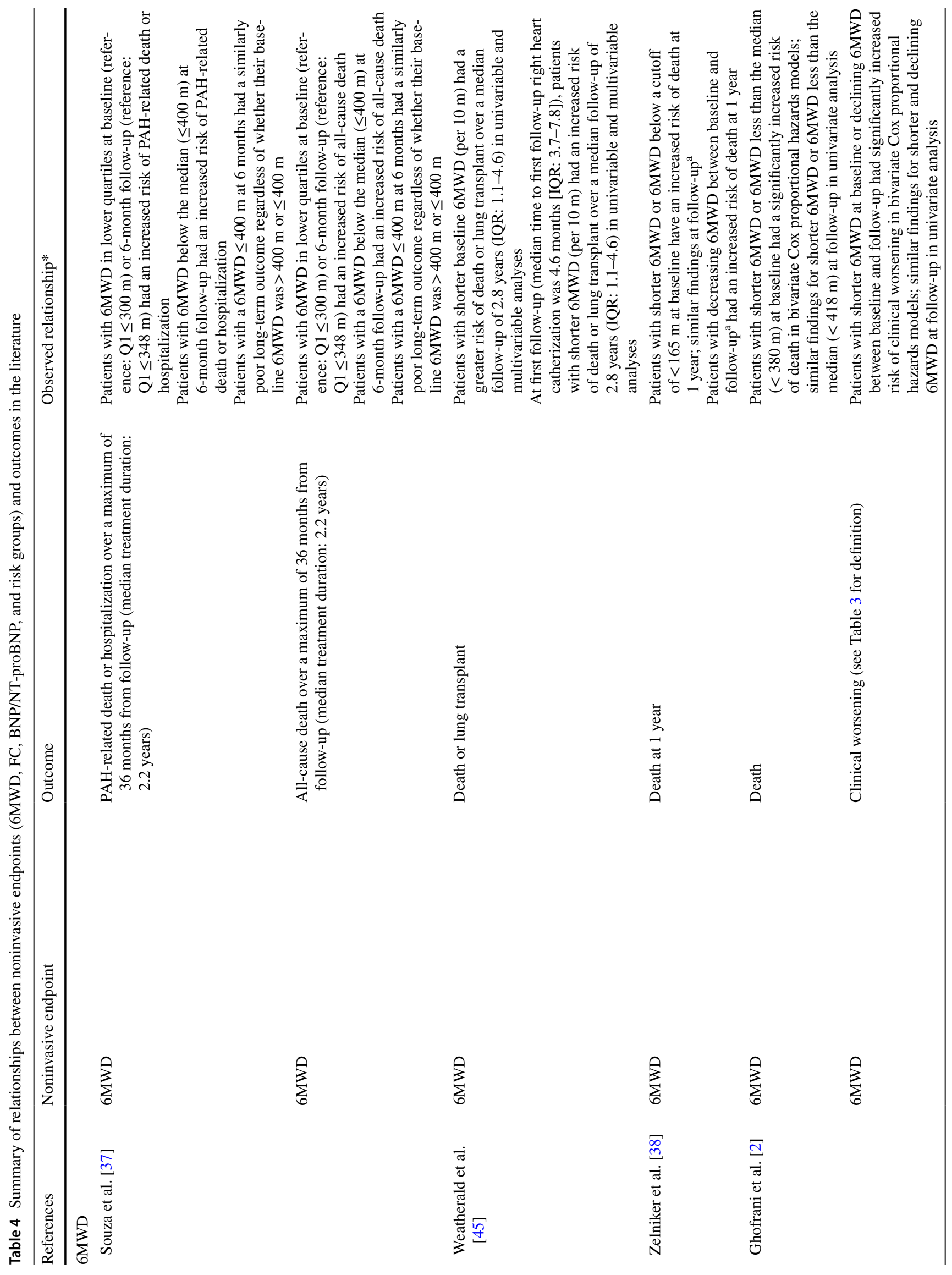




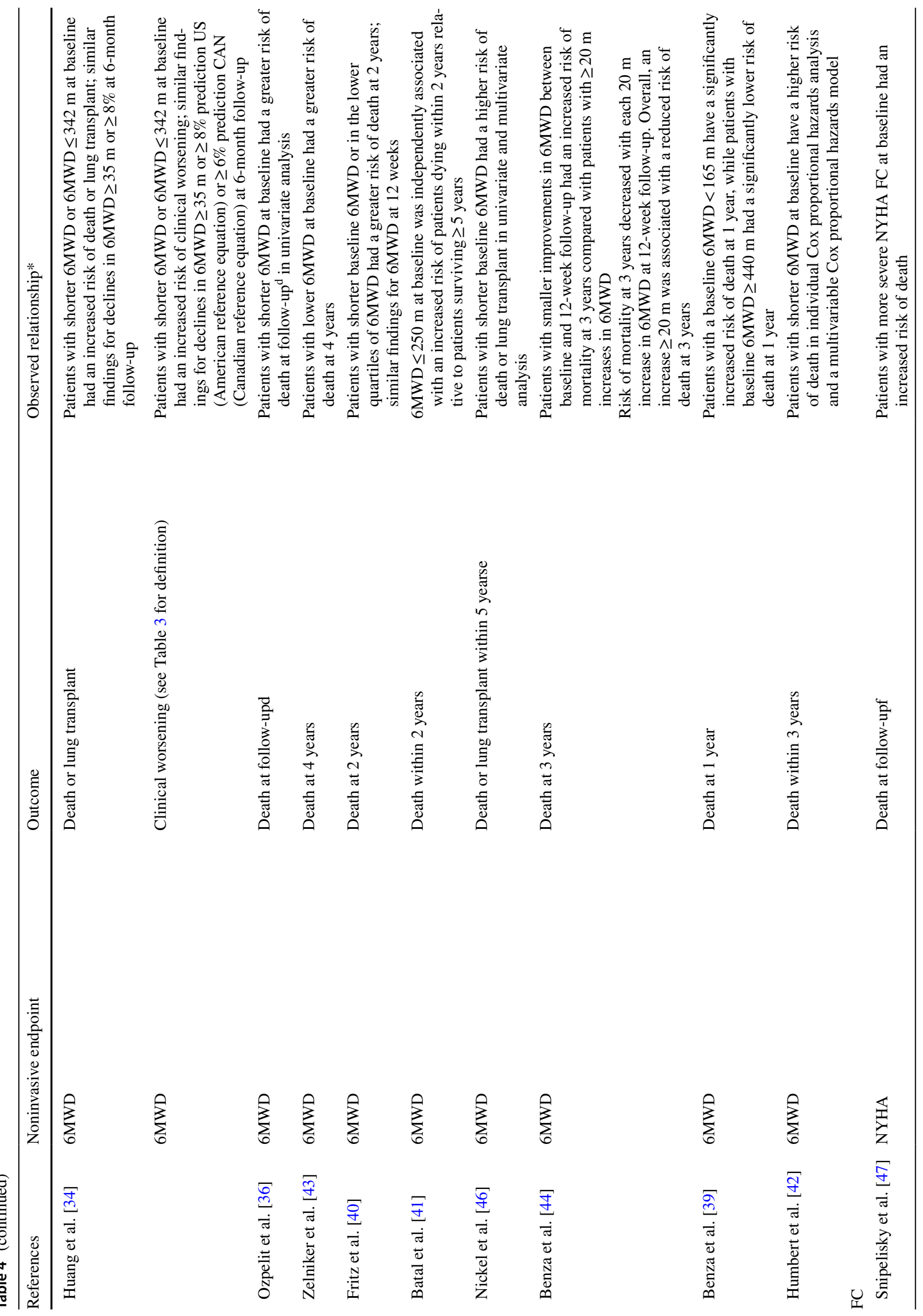




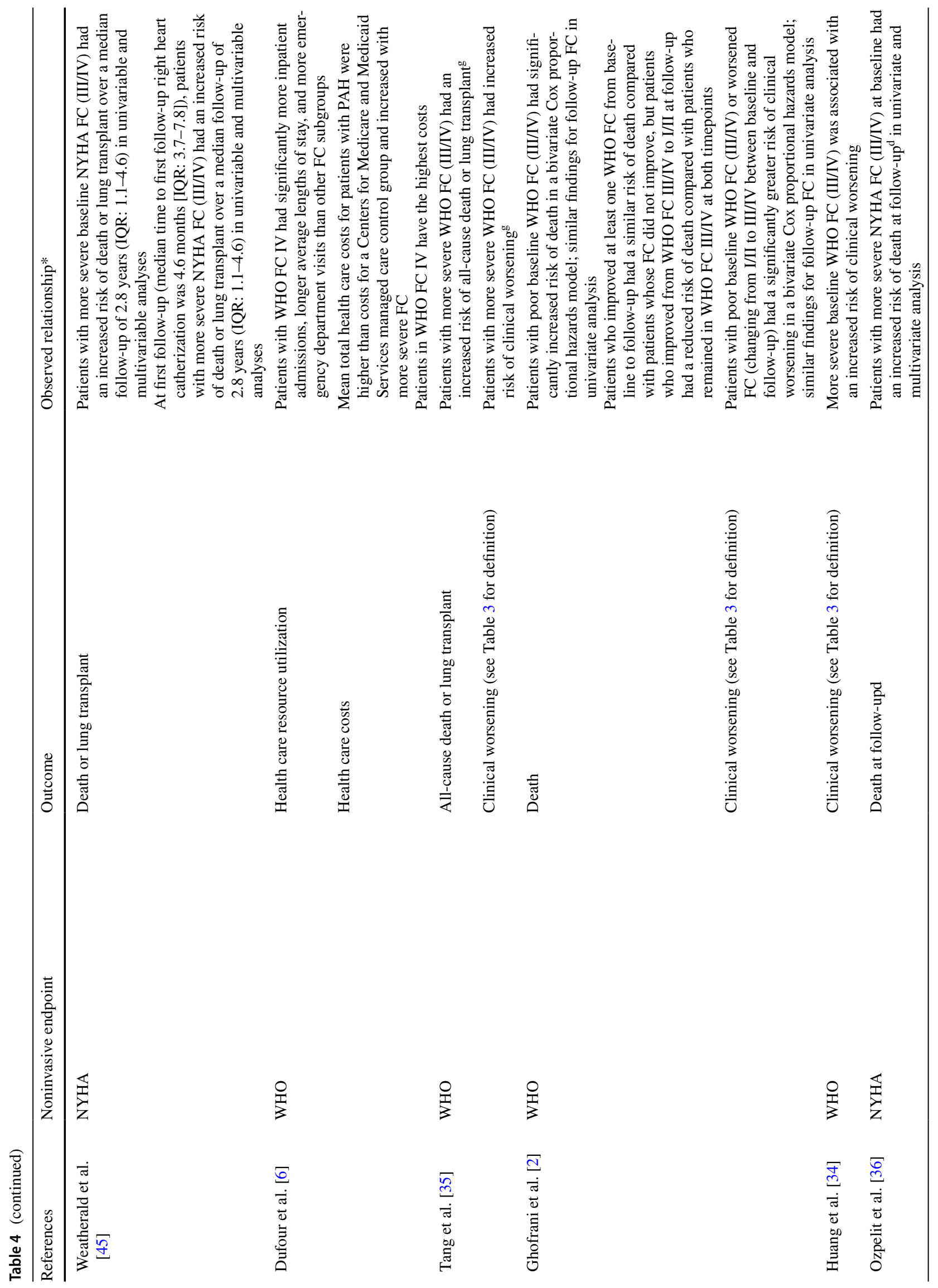




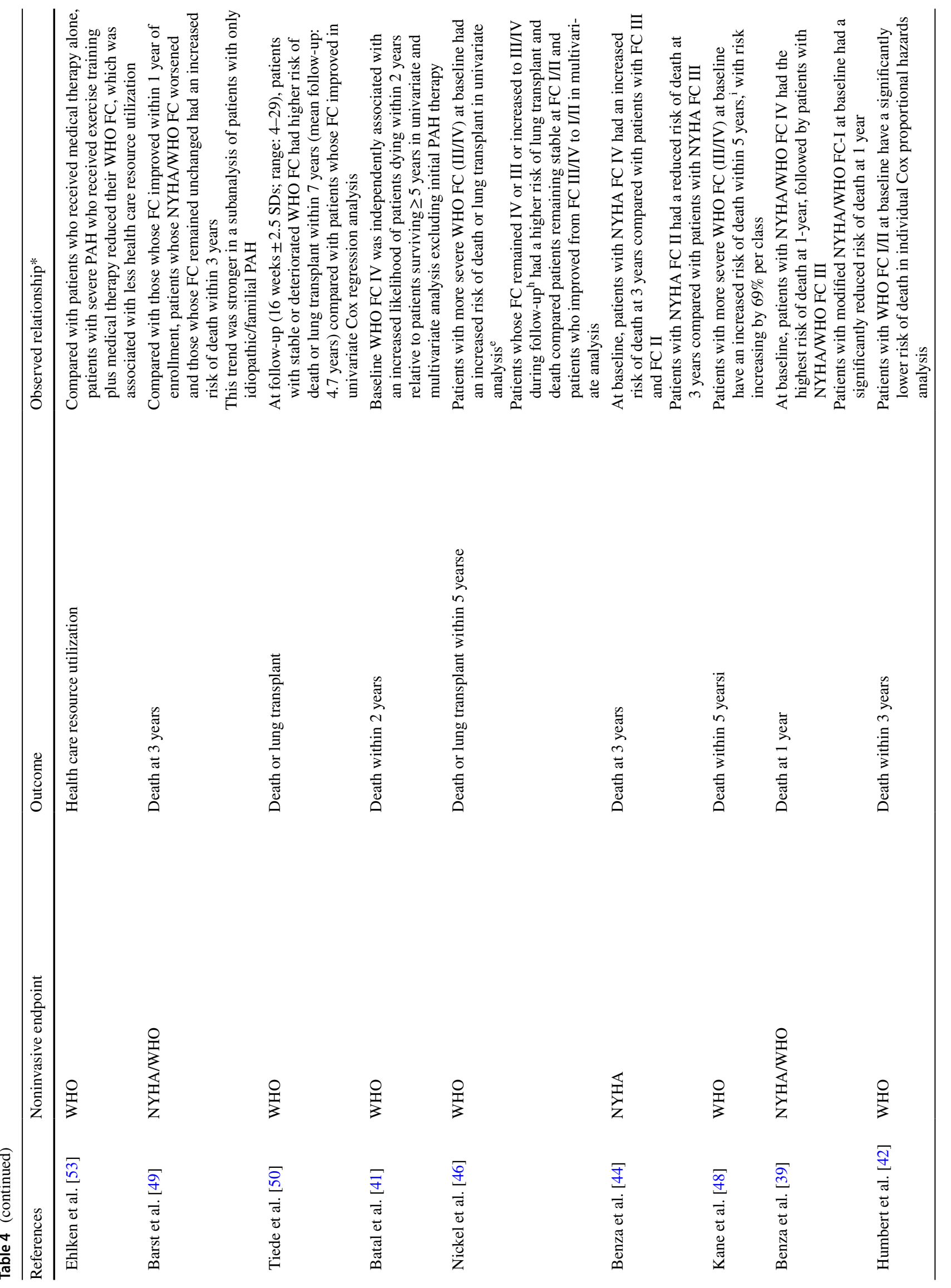




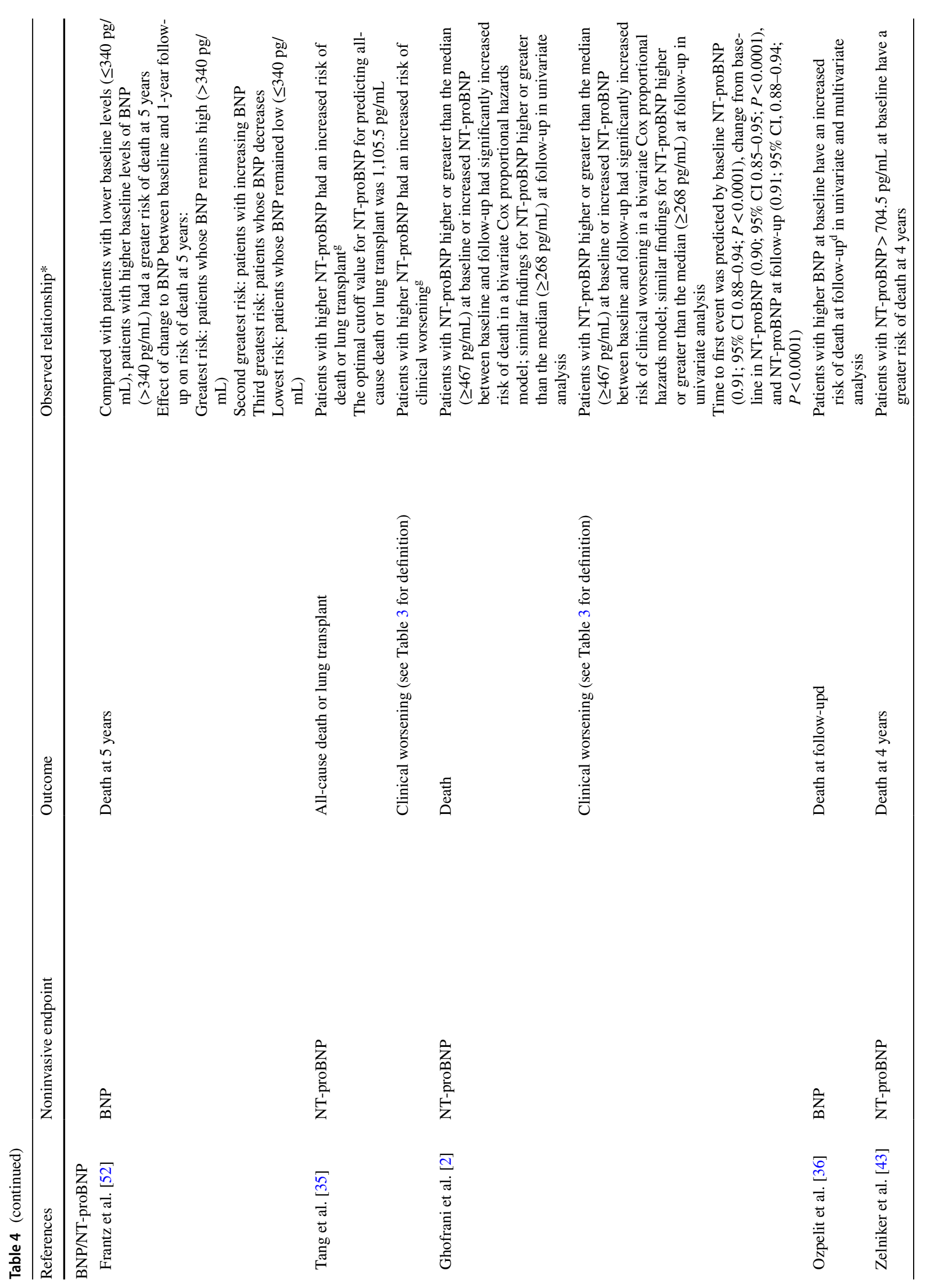




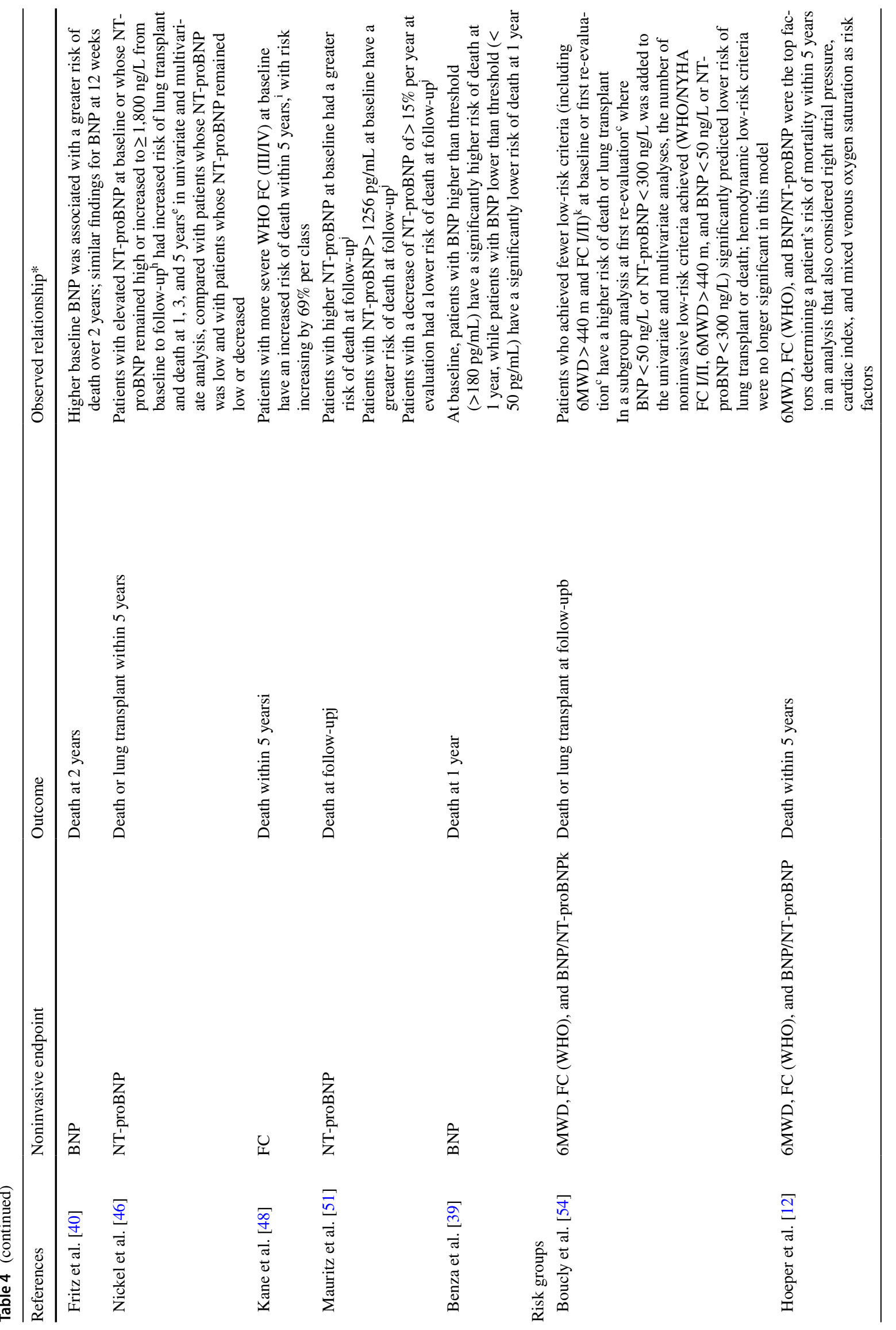




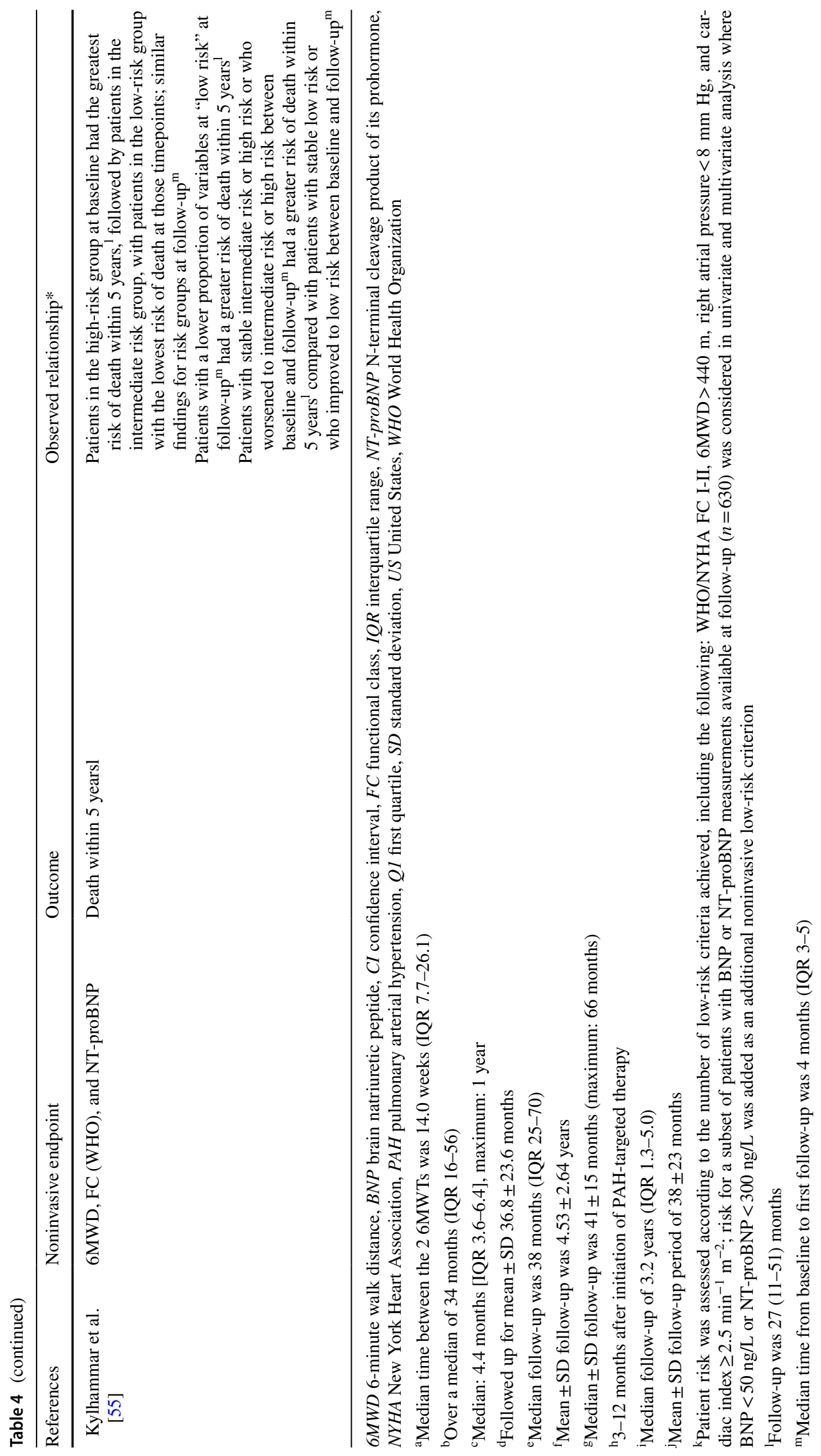


FC remained III or IV or increased to III/IV during followup compared with patients who remained at FC I/II and patients who improved from FC III/IV to I/II [46]. Within 7 years, risk of death or lung transplant similarly increased for patients with stable or deteriorated FC compared with patients whose FC improved [50].

\section{FC and Risk of Clinical Worsening}

Risk of clinical worsening was increased among patients with more severe FC (III/IV) at baseline [2, 34, 35]. More severe FC (III/IV) at follow-up or FC that worsened (from I/II to III/IV) between baseline and follow-up also predicted clinical worsening [2].

\section{BNP/NT-proBNP}

Nine studies evaluated the relationship between BNP/NTproBNP and risk of death $(n=7)$, experiencing a costly event indicative of clinical worsening $(n=2)$, and death or lung transplant $(n=2)$ (Table 4). The frequency of use of BNP (four studies) and NT-proBNP (five studies) was similar in the literature, with no clear temporal differences by year of publication or study start date.

\section{BNP/NT-proBNP and Risk of Death}

Risk of death was increased for patients with higher BNP [36] or NT-proBNP at baseline [2, 51] or NT-proBNP above the median ( $\geq 467 \mathrm{pg} / \mathrm{mL}$ ) [2] or cutoff ( $>1256 \mathrm{pg} /$ $\mathrm{mL}$ ) at baseline [51]. Risk of death at 1 year was increased for patients with BNP higher than the threshold (>180 pg/ $\mathrm{mL}$ ) at baseline [39]. Risk of death at 2 years was increased among patients with higher BNP at baseline [40]. At 4 years, risk of death was increased among patients with NT-proBNP $>704.5 \mathrm{pg} / \mathrm{mL}$ at baseline [43]. Increased risk of death at 5 years was associated with baseline levels of $\mathrm{BNP}>340 \mathrm{pg} / \mathrm{mL}$ [52].

Risk of death also increased for patients whose NTproBNP was higher [2], greater than the median ( $\geq 268 \mathrm{pg}$ / $\mathrm{mL}$ ) [2], or increased between baseline and follow-up [2, 51]. Risk of death at 2 years, in particular, was increased among patients with elevated BNP at the week 12 assessment [40]. Risk of death at 5 years was highest among patients whose BNP remained high ( $>340 \mathrm{pg} / \mathrm{mL})$, followed by patients with increased BNP at 1 year of follow-up; patients whose BNP decreased or remained low $(\leq 340 \mathrm{pg}$ / $\mathrm{mL}$ ) at 1 year of follow-up had the lowest risk [52].

\section{NT-proBNP and Risk of Death or Lung Transplant}

Risk of death or lung transplant was increased for patients with elevated NT-proBNP at baseline [35, 46]. An optimal cutoff of NT-proBNP $>1105.5 \mathrm{pg} / \mathrm{mL}$ at baseline predicted risk of all-cause death or lung transplant [35]. Risk of death at 1,3 , and 5 years was increased among patients whose NT-proBNP remained high or increased to $\geq 1800 \mathrm{ng} / \mathrm{L}$ at follow-up [46].

\section{NT-proBNP and Risk of Clinical Worsening}

Risk of clinical worsening was increased among patients with NT-proBNP that was elevated $[2,35]$ or greater than the median $(\geq 467 \mathrm{pg} / \mathrm{mL})$ at baseline [2]. Risk of clinical worsening was also increased among patients with elevated or increased NT-proBNP at follow-up [2].

\section{FC and Economic Outcomes}

Mean total health care costs for patients with PAH were higher than costs for a Centers for Medicare and Medicaid Services managed care control group and increased with more severe baseline FC, with patients in FC IV having the highest costs [6]. Health care resource utilization, including inpatient admissions, longer average lengths of stay, and emergency department visits, was also greater for patients with FC IV than other FC subgroups [6]. In another study, patients with severe PAH who received medical therapy alone were more likely to have more severe FC (III/IV), which was associated with greater health care resource utilization compared with patients who received exercise training plus medical therapy [53].

\section{MWD, FC, and BNP/NT-proBNP Risk Groups}

Three studies evaluated the relationship between risk group and death within 5 years $(n=2)$ and death or lung transplant $(n=1)$ (Table 4). The 2015 European Society of Cardiology (ESC)/European Respiratory Society (ERS) guidelines were used to stratify patients as low, intermediate, or high risk $[12,54,55]$. All three studies considered FC and 6MWD when determining risk $[12,54,55]$ (Table 4). Two considered BNP/NT-proBNP in the primary determination of risk $[12,55]$, while one study considered the additive value of $\mathrm{BNP}<50 \mathrm{ng} \mathrm{L}^{-1}$ or NT-proBNP $<300 \mathrm{ng} \mathrm{L}^{-1}$ low-risk criteria [54]. Additional factors considered in determining risk included right atrial pressure, cardiac index, mixed venous oxygen saturation $[12,54,55]$, right atrial area, and pericardial effusion [55]. Risk was determined by a mean score calculated using the sum of the grades assigned to each risk factor from 1 (low risk) to 3 (high risk) and dividing by the total number of risk factors $[12,55]$ and by the number of low-risk criteria present at baseline and re-evaluation (FC I-II, 6MWD $>440 \mathrm{~m}$, right atrial pressure $<8 \mathrm{~mm} \mathrm{Hg}$ and cardiac index $\geq 2.5 \mathrm{~min}^{-1} \mathrm{~m}^{-2}$ ) [54]. 


\section{Risk Groups and Risk of Death}

Risk of death within 5 years was increased among patients with a higher proportion of "high-risk" variables at both baseline and follow-up, determined with the inclusion of 6MWD, FC, and NT-proBNP [55]. 6MWD followed by FC and BNP/NT-proBNP most strongly correlated with a patient's risk of death within 5 years [12].

\section{Risk Groups and Risk of Death or Lung Transplant}

At baseline, all four low-risk criteria significantly predicted risk of death or lung transplant in univariable analysis; $6 \mathrm{MWD}>440 \mathrm{~m}$ was the only low-risk criterion remaining significant in multivariable analysis [54]. At first re-evaluation, all four low-risk criteria significantly predicted risk of death or lung transplant in univariate and multivariable analysis [54]. Outcomes were similar for patients who had an increase in the number of low-risk criteria achieved between baseline and first re-evaluation ( $<3$ to having $3-4)$ and those who had 3-4 low-risk variables at both time points. Patients with less than three low-risk criteria at both baseline and first revaluation had the greatest risk of death or lung transplant; for patients with zero low-risk variables at follow-up, transplant-free survival was worse for those with two high-risk variables than for those with one. In the subgroup of patients who had all three noninvasive measurements at follow-up, risk of death or lung transplant was significantly lower for patients who achieved one or more low-risk criteria (FC I-II, $6 \mathrm{MWD}>440 \mathrm{~m}, \mathrm{BNP}<50 \mathrm{ng} \mathrm{L}^{-1}$ ); in this multivariable model, hemodynamic low-risk criteria (right atrial pressure $<8 \mathrm{~mm} \mathrm{Hg}$ and cardiac index $\geq 2.5 \mathrm{~min}^{-1} \mathrm{~m}^{-2}$ ) were no longer significant predictors of transplant-free survival [54].

\section{Discussion}

This review provides support for 6MWD, FC, and BNP/ NT-proBNP as correlates of risk of long-term health outcomes (e.g., mortality and clinical worsening), costly events (e.g., lung transplants or hospitalization), and economic outcomes (e.g., costs and resource utilization) in PAH. Relative to patients with longer or increased 6MWD, patients with shorter or decreased 6MWD have a higher risk of death and experiencing costly events indicative of clinical worsening, such as hospitalization or lung transplant. Compared to patients with more favorable (I or II) or improved FC, patients with poorer (III or IV) or declined FC consume greater health care resources, incur higher health care costs, and are at an increased risk of death and clinical worsening. Patients with elevated or increased BNP/NT-proBNP have a higher risk of death and clinical worsening relative to patients with lower or decreased BNP/NT-proBNP. In addition, patients classified into more severe risk groups, determined by multiple noninvasive endpoints (e.g., 6MWD, FC, and BNP/NT-proBNP), have an increased risk of death and lung transplant.

These findings are important considering the current shift from using these noninvasive measures as primary and secondary endpoints in PAH clinical trials to evaluating mortality and clinical worsening in clinical trials. A related review has also concluded that 6MWD and FC are clinically meaningful trial endpoints associated with outcomes in patients with PAH and CTEPH [16]. While mortality and clinical worsening are robust and valuable long-term endpoints in clinical trials, 6MWD, FC, and BNP/NT-proBNP remain informative prognostic indicators that can be used in the clinic to assess and reduce risk of death or costly events for patients with PAH [15]. Whereas multiple definitions are used for clinical worsening across trials, $6 \mathrm{MWD}, \mathrm{FC}$, and BNP/NT-proBNP are universally defined and recognized, enabling comparisons of treatment efficacy across trials using these endpoints. 6MWD and FC are already being included in the composite endpoint of clinical worsening in many trials and in risk calculators such as REVEAL 2.0 [13]. BNP/NT-proBNP is also included in risk calculators [13] and is a prominent biomarker used in clinical management $[56,57]$ as well as part of the multiparametric risk assessment approach outlined in guidelines [58]. These noninvasive endpoints are simpler and more inexpensive to assess relative to event-based endpoints [14]. For instance, morbidity and mortality event trials require a large number of subjects in order to demonstrate effects even as early as 1 year $[59,60]$. Looking to the future, consideration should be given to including 6MWD, FC, and BNP/NT-proBNP in the assessment of time to clinical improvement, a new endpoint proposed at the recent 6th World Symposium on Pulmonary Hypertension [61].

Conclusions from the present review should be considered with caution because no pooled analysis was performed to evaluate the observed relationships between the noninvasive endpoints and long-term outcomes for statistical significance. Previous meta-analyses and pooled analyses for 6MWD have found no correlation between 6MWD and mortality [21] and clinical events [22] or only modest validity for 6MWD as a surrogate endpoint [18]. Given that the majority of studies evaluating 6MWD included in this review were published after these studies were conducted (10 of 13 studies), an updated analysis is needed in order to confirm our observations. In addition, the paucity of literature evaluating health care resource utilization and costs in PAH limits the ability to draw conclusions on the predictive nature of noninvasive endpoints in terms of economic outcomes. However, given what is known about the relationships between noninvasive endpoints and events, such as hospitalization and lung transplant, the economic impact may be extrapolated using 
existing data on the costs of those events. Further, our review did not consider the predictive value of additional variables that are considered in risk assessments such as cardiopulmonary exercise testing, imaging (e.g., echocardiogram, cardiac magnetic resonance imaging), hemodynamics, and right heart catherization $[13,56]$. While these variables are important, our review focused on the noninvasive endpoints most commonly used in clinical trials and risk assessments that are most efficient and inexpensive to assess.

\section{Conclusions}

Mortality and clinical worsening will continue to be valuable endpoints in assessing treatment efficacy and safety in $\mathrm{PAH}$; however, these endpoints require lengthy follow-up and cannot be applied in clinical settings where risk reduction is the goal of treatment. Further, differing definitions used for clinical worsening across trials limit the ability of stakeholders to compare treatment efficacy. 6MWD, FC, and BNP/NT-proBNP are universally defined, low-cost, efficient, noninvasive endpoints that correlate with long-term health and economic outcomes in patients with PAH. Collectively, they are important components of risk assessments and will remain beneficial in the clinic to guide treatment decisions. Future research should meta-analytically examine the relationships between these noninvasive endpoints and longterm outcomes for statistical significance. Additional studies are needed examining the relationship between $6 \mathrm{MWD}$, FC, and BNP/NT-proBNP and economic outcomes and the potential utility of $6 \mathrm{MWD}, \mathrm{FC}$, and BNP/NT-proBNP as a composite endpoint assessing risk.

Funding United therapeutics supported this research.

\section{Compliance with Ethical Standards}

Conflict of interest Samantha Wronski and Margaret Mordin are employees of RTI Health Solutions. Kim Kelley is business owner of Rx Trusted Advisors, PLLC which works with life science and futurist groups, along with peer to peer learning, pipeline strategy sessions. And additional work advising in high cost pharmacy and medical cases. Previous Director of Pharmacy for BlueCross and BlueShield of Arizona. Groups and organizations I have worked directly or indirectly with or own stock include; Rx Worldwide Meetings, Navigant Life Sciences, Amgen, Novartis, UCB, Gerson Lehrman Group Councel, Lilly, United Therapeutics Corporation, CB Partner, McCann Health, ClearView Health Partners, Parallax Life Sciences, Insmed, Integrated Healthcare Management, Business Talent Group, Evidera, and River West Meeting Associates. Dr. Anguiano is on the speaker's bureau and advisory board for United Therapeutics. Peter Classi is an employee and minor shareholder in United Therapeutics Corporation. Eric Shen is an employee of United Therapeutics Corporation. Scott Manaker is a Grand Rounds speaker, lecturer, consultant, and expert witness on documentation, coding, billing, and reimbursement to hospitals, physicians, departments, practice groups, professional societies, insurers, and attorneys (defense, plaintiff "qui tam", US Attorneys General, and the Office of the Inspector General). Consultant to Apnicure, Aetna, Pfizer, Novartis and Johnson \& Johnson. Expert witness in workers' compensation and in medical negligence matters. Chair, Practice Expense Subcommittee of the American Medical Association/Specialty Society Relative Value Update Committee (RUC). Member, Hospital Outpatient Panel, a federal advisory commission to the Center for Medicare/Medicaid Services (CMS) for the Outpatient Hospital Prospective Payment System. Stock held in 3M; and (by spouse) in Pfizer, Johnson \& Johnson. Director of ACCP Enterprises, a wholly owned for-profit subsidiary of ACCP. Section Editor (Critical Care), UpToDate. Associate Editor, CHEST Journal. Trustee, National Board for Respiratory Care.

Open Access This article is distributed under the terms of the Creative Commons Attribution 4.0 International License (http://creativeco mmons.org/licenses/by/4.0/), which permits unrestricted use, distribution, and reproduction in any medium, provided you give appropriate credit to the original author(s) and the source, provide a link to the Creative Commons license, and indicate if changes were made.

\section{References}

1. Frost AE, Badesch DB, Barst RJ et al (2011) The changing picture of patients with pulmonary arterial hypertension in the United States: how REVEAL differs from historic and non-US Contemporary Registries. Chest 139(1):128-137

2. Ghofrani H, Grimminger F, Grünig E et al (2016) Predictors of long-term outcomes in patients treated with riociguat for pulmonary arterial hypertension: data from the PATENT-2 openlabel, randomised, long-term extension trial. Lancet Respir Med 4(5):361-371

3. Lan NSH, Massam BD, Kulkarni SS, Lang CC (2018) Pulmonary arterial hypertension: pathophysiology and treatment. Diseases 6(2):38

4. Burger CD, Ghandour M, Padmanabhan Menon D, Helmi H, Benza RL (2017) Early intervention in the management of pulmonary arterial hypertension: clinical and economic outcomes. Clinicoecon Outcomes Res 9:731-739

5. Burke JP, Hunsche E, Regulier E, Nagao M, Buzinec P, Drake Iii W (2015) Characterizing pulmonary hypertension-related hospitalization costs among Medicare Advantage or commercially insured patients with pulmonary arterial hypertension: a retrospective database study. Am J Manag Care 21(3 Suppl):s47-58

6. Dufour R, Pruett J, Hu N et al (2017) Healthcare resource utilization and costs for patients with pulmonary arterial hypertension: real-world documentation of functional class. J Med Econ 20(11):1178-1186

7. Lajoie AC, Bonnet S, Lacasse Y, Lega J-C, Provencher S (2018) Interpreting risk reduction in clinical trials for pulmonary arterial hypertension. Eur Respir Rev 27(148): 180020

8. Galiè N, Channick RN, Frantz RP et al (2019) Risk stratification and medical therapy of pulmonary arterial hypertension. Eur Respir J 53(1): 1801889

9. Parikh KS, Rajagopal S, Arges K et al (2015) Use of outcome measures in pulmonary hypertension clinical trials. Am Heart J 170(3):419-429.e413

10. Raina A, Humbert M (2016) Risk assessment in pulmonary arterial hypertension. Eur Respir Rev 25(142):390-398

11. Galiè N, Humbert M, Vachiery J-L et al (2015) 2015 ESC/ERS Guidelines for the diagnosis and treatment of pulmonary hypertension. Eur Respir J 46(4):903 
12. Hoeper MM, Kramer T, Pan Z et al (2017) Mortality in pulmonary arterial hypertension: prediction by the 2015 European pulmonary hypertension guidelines risk stratification model. Eur Respir J 50(2): 1700740

13. Benza RL, Gomberg-Maitland M, Elliott CG et al (2019) Predicting survival in patients with pulmonary arterial hypertension: the REVEAL risk score calculator 2.0 and comparison with ESC/ ERS-based risk assessment strategies. Chest 156:323-337

14. Snow JL, Kawut SM (2007) Surrogate end points in pulmonary arterial hypertension: assessing the response to therapy. Clin Chest Med 28(1):75-89

15. Zamanian RT, Kudelko KT, Sung YK, Perez VdJ, Liu J, Spiekerkoetter E (2014) Current clinical management of pulmonary arterial hypertension. Circ Res 115(1):131-147

16. Divers C, Platt D, Wang E, Lin J, Lingohr-Smith M, Mathai SC (2017) A review of clinical trial endpoints of patients with pulmonary arterial hypertension and chronic thromboembolic pulmonary hypertension and how they relate to patient outcomes in the United States. J Manag Care Spec Pharm 23(1):92-104

17. Farber HW, Miller DP, McGoon MD, Frost AE, Benton WW, Benza RL (2015) Predicting outcomes in pulmonary arterial hypertension based on the 6-minute walk distance. J Heart Lung Transplant 34(3):362-368

18. Gabler NB, French B, Strom BL, Palevsky HI, Taichman DB, Kawut SM, Halpern SD (2012) Validation of 6-minute walk distance as a surrogate end point in pulmonary arterial hypertension trials. Circulation 126(3):349-356

19. Gomberg-Maitland M, Bull TM, Saggar R et al (2013) New trial designs and potential therapies for pulmonary artery hypertension. J Am Coll Cardiol 62(25 Suppl):D82-D91

20. Hill NS, Cawley MJ, Heggen-Peay CL (2016) New therapeutic paradigms and guidelines in the management of pulmonary arterial hypertension. J Manag Care Spec Pharm 22(3-a Suppl):s3-s21.

21. Macchia A, Marchioli R, Marfisi R, Scarano M, Levantesi G, Tavazzi L, Tognoni G (2007) A meta-analysis of trials of pulmonary hypertension: A clinical condition looking for drugs and research methodology. Am Heart J 153(6):1037-1047

22. Savarese G, Paolillo S, Costanzo P et al (2012) Do changes of 6-minute walk distance predict clinical events in patients with pulmonary arterial hypertension? A meta-analysis of 22 randomized trials. J Am Coll Cardiol 60(13):1192-1201

23. Studer SM, Gilkin RJ Jr (2014) Clinical trial designs in PAH: shifting from functional measurements to long-term clinical outcomes. Am J Manag Care 20(6 Suppl):S115-122

24. Vachiéry J-L, Yerly P, Huez S (2012) How to detect disease progression in pulmonary arterial hypertension. Eur Respir Rev 21(123):40-47

25. Waxman AB, Farber HW (2015) Using clinical trial end points to risk stratify patients with pulmonary arterial hypertension. Circulation 132(22):2152-2161

26. Chakinala MM, Barst R (2013) From short-term benefits to longterm outcomes: the evolution of clinical trials in pulmonary arterial hypertension. Pulm Circ 3(3):507-522

27. Galiè N, Barberà JA, Frost AE et al (2015) Initial use of ambrisentan plus tadalafil in pulmonary arterial hypertension. N Engl $\mathrm{J}$ Med 373(9):834-844

28. Sitbon O, Channick R, Chin KM et al (2015) Selexipag for the treatment of pulmonary arterial hypertension. N Engl J Med 373(26):2522-2533

29. Pulido T, Adzerikho I, Channick RN et al (2013) Macitentan and morbidity and mortality in pulmonary arterial hypertension. $\mathrm{N}$ Engl J Med 369(9):809-818

30. Tapson VF, Sanchez Diaz CJ, Bohns Meyer GM et al (2019) Treatment with oral treprostinil delays time to clinical worsening in patients with pulmonary arterial hypertension - results from FREEDOM-EV. J Heart Lung Transplant 38(4):S94-S95

31. White RJ, Sanchez Diaz CJ, Bohns Meyer GM, Pulido T, Sepulveda P, Wang KY, et al (2019) Treatment with oral treprostinil is associated with improved survival in pulmonary arterial hypertension participants from the FREEDOM-EV study. In: 13th Pulmonary Vascular Research Institute (PVRI) Annual World Congress on PVD. Barcelona, Spain

32. White RJ, Jerjes-Sanchez C, Bohns Meyer GM, Pulido T, Sepulveda P, Wang KY et al (2019) Risk scores and risk-based stratification of clinical worsening events in pulmonary arterial hypertension participants treated with oral treprostinil: FREEDOM-EV. Am J Respir Crit Care Med 199(Suppl):A5587-A5587

33. Newman JH, Rich S, Abman SH et al (2017) Enhancing insights into pulmonary vascular disease through a precision medicine approach A joint NHLBI-Cardiovascular Medical Research and Education Fund Workshop report. Am J Respir Crit Care Med 195(12):1661-1670

34. Huang J, Mehta S, Mura M (2015) Early decline in six-minute walk distance from the time of diagnosis predicts clinical worsening in pulmonary arterial hypertension. Respiration 89(5):365-373

35. Tang Y, Luo Q, Liu Z et al (2017) Oxygen uptake efficiency slope predicts poor outcome in patients with idiopathic pulmonary arterial hypertension. J Am Heart Assoc 6(7):e005037

36. Ozpelit E, Akdeniz B, Ozpelit ME et al (2015) Prognostic value of neutrophil-to-lymphocyte ratio in pulmonary arterial hypertension. J Int Med Res 43(5):661-671

37. Souza R, Channick RN, Delcroix M et al (2018) Association between six-minute walk distance and long-term outcomes in patients with pulmonary arterial hypertension: Data from the randomized SERAPHIN trial. PLoS ONE 13(3):e0193226

38. Zelniker TA, Huscher D, Vonk-Noordegraaf A et al (2018) The 6MWT as a prognostic tool in pulmonary arterial hypertension: results from the COMPERA registry. Clin Res Cardiol 107:460-470

39. Benza RL, Miller DP, Gomberg-Maitland M et al (2010) Predicting survival in pulmonary arterial hypertension: insights from the Registry to Evaluate Early and Long-Term Pulmonary Arterial Hypertension Disease Management (REVEAL). Circulation 122(2):164-172

40. Fritz JS, Blair C, Oudiz RJ et al (2013) Baseline and followup 6-min walk distance and brain natriuretic peptide predict 2 -year mortality in pulmonary arterial hypertension. Chest 143(2):315-323

41. Batal O, Khatib OF, Dweik RA, Hammel JP, McCarthy K, Minai OA (2012) Comparison of baseline predictors of prognosis in pulmonary arterial hypertension in patients surviving $\leq 2$ years and those surviving $\% 3 \mathrm{c} 5$ years after baseline right-sided cardiac catheterization. Am J Cardiol 109(10):1514-1520

42. Humbert M, Sitbon O, Chaouat A et al (2010) Survival in patients with idiopathic, familial, and anorexigen-associated pulmonary arterial hypertension in the modern management era. Circulation 122(2):156-163

43. Zelniker T, Uhlmann L, Spaich S et al (2015) Novel biomarkers for risk stratification in pulmonary arterial hypertension. ERJ Open Res 1(2):00008

44. Benza RL, Seeger W, McLaughlin VV et al (2011) Long-term effects of inhaled treprostinil in patients with pulmonary arterial hypertension: the Treprostinil Sodium Inhalation Used in the Management of Pulmonary Arterial Hypertension (TRIUMPH) study open-label extension. J Heart Lung Transplant 30(12):1327-1333

45. Weatherald J, Boucly A, Chemla D et al (2018) Prognostic value of follow-up hemodynamic variables after initial management in pulmonary arterial hypertension. Circulation 137(7):693-704 
46. Nickel N, Golpon H, Greer M et al (2012) The prognostic impact of follow-up assessments in patients with idiopathic pulmonary arterial hypertension. Eur Respir J 39(3):589-596

47. Snipelisky D, Jentzer J, Batal O, Dardari Z, Mathier M (2018) Serum albumin concentration as an independent prognostic indicator in patients with pulmonary arterial hypertension. Clin Cardiol 41:782-787

48. Kane GC, Maradit-Kremers H, Slusser JP, Scott CG, Frantz RP, McGoon MD (2011) Integration of clinical and hemodynamic parameters in the prediction of long-term survival in patients with pulmonary arterial hypertension. Chest 139(6):1285-1293

49. Barst RJ, Chung L, Zamanian RT, Turner M, McGoon MD (2013) Functional class improvement and 3-year survival outcomes in patients with pulmonary arterial hypertension in the REVEAL Registry. Chest 144(1):160-168

50. Tiede H, Sommer N, Milger K et al (2013) Short-term improvement in pulmonary hemodynamics is strongly predictive of longterm survival in patients with pulmonary arterial hypertension. Pulm Circ 3(3):523-532

51. Mauritz GJ, Rizopoulos D, Groepenhoff H et al (2011) Usefulness of serial N-terminal pro-B-type natriuretic peptide measurements for determining prognosis in patients with pulmonary arterial hypertension. Am J Cardiol 108(11):1645-1650

52. Frantz RP, Farber HW, Badesch DB et al (2018) Baseline and serial brain natriuretic peptide level predicts 5-year overall survival in patients with pulmonary arterial hypertension: data from the REVEAL registry. Chest 154:126-135

53. Ehlken N, Verduyn C, Tiede H et al (2014) Economic evaluation of exercise training in patients with pulmonary hypertension. Lung 192(3):359-366

54. Boucly A, Weatherald J, Savale L et al (2017) Risk assessment, prognosis and guideline implementation in pulmonary arterial hypertension. Eur Respir J 50(2):1700889

55. Kylhammar D, Kjellstrom B, Hjalmarsson C et al (2018) A comprehensive risk stratification at early follow-up determines prognosis in pulmonary arterial hypertension. Eur Heart J 39(47):4175-4181
56. Galie N, Humbert M, Vachiery JL et al (2016) 2015 ESC/ERS guidelines for the diagnosis and treatment of pulmonary hypertension: The Joint Task Force for the diagnosis and treatment of pulmonary hypertension of the European Society of Cardiology (ESC) and the European Respiratory Society (ERS): endorsed by: Association for European Paediatric and Congenital Cardiology (AEPC), International Society for Heart and Lung Transplantation (ISHLT). Eur Heart J 37(1):67-119

57. Iannuzzi GL, D’Alto M, Formisano R, Maniscalco M (2019) Biomarkers in clinical management of pulmonary hypertension: has the emperor no clothes? A call for action. Biomark Med 13(4):235-238

58. Chin KM, Rubin LJ, Channick R et al (2019) Association of $\mathrm{N}$-terminal pro brain natriuretic peptide and long-term outcome in patients with pulmonary arterial hypertension. Circulation 139(21):2440-2450

59. Weatherald J, Boucly A, Sahay S, Humbert M, Sitbon O (2018) The low-risk profile in pulmonary arterial hypertension Time for a paradigm shift to goal-oriented clinical trial endpoints? Am J Respir Crit Care Med 197(7):860-868

60. McLaughlin VV, Hoeper MM, Channick RN et al (2018) Pulmonary arterial hypertension-related morbidity is prognostic for mortality. J Am Coll Cardiol 71(7):752-763

61. Sitbon O, Gomberg-Maitland M, Granton J et al (2019) Clinical trial design and new therapies for pulmonary arterial hypertension. Eur Respir J 53(1):1801908

62. McLaughlin VV, McGoon MD (2006) Pulmonary arterial hypertension. Circulation 114(13):1417-1431

63. Cleveland Clinic (2017) NT-proB-type natriuretic peptide (BNP). https://my.clevelandclinic.org/health/diagnostics/16814-nt-probtype-natriuretic-peptide-bnp. Accessed 23 Aug 2018.

Publisher's Note Springer Nature remains neutral with regard to jurisdictional claims in published maps and institutional affiliations. 